\title{
Prenatal Diagnosis of Lissencephaly Type 2 using Three-dimensional Ultrasound and Fetal MRI: Case Report and Review of the Literature
}

\section{Diagnóstico pré-natal de lissencefalia tipo 2 por meio da ultrassonografia e ressonância magnética fetal: relato de caso e revisão da literatura}

\author{
${ }^{1}$ Department of Obstetrics \& Gynecology, Ospedale Civile Guastalla, \\ AUSL Reggio Emilia, Reggio Emilia, Italy \\ 2 Department of Diagnostic Imaging, Istituto di Ricovero e Cura a \\ Carattere Scientifico (IRCCS) "Arcispedale Santa Maria Nuova", \\ Reggio Emilia, Italy \\ ${ }^{3}$ Department of Pathology, Istituto di Ricovero e Cura a Carattere \\ Scientifico (IRCCS) "Arcispedale Santa Maria Nuova”, Reggio Emilia, \\ Italy \\ ${ }^{4}$ Department of Obstetrics, Escola Paulista de Medicina, Universidade \\ Federal de São Paulo (EPM-Unifesp), São Paulo-SP, Brazil
}

Gabriele Tonni ${ }^{1}$ Pierpaolo Pattacini ${ }^{2}$ Maria Paola Bonasoni ${ }^{3} \quad$ Edward Araujo Júnior ${ }^{4}$

Address for correspondence Edward Araujo Júnior, MD, PhD, Departmento de Obstetrícia, Escola Paulista de MedicinaUniversidade Federal de São Paulo (EPM-Unifesp), Rua Napoleão de Barros 875, Vila Clementino, 04024-002, São Paulo-SP, Brazil (e-mail: araujojred@terra.com.br).

Rev Bras Ginecol Obstet 2016;38:201-206.

\footnotetext{
Abstract

Keywords

- lissencephaly

- cobblestone cortex

- genetic counseling

- magnetic resonance imaging

- pathology

- prenatal diagnosis

- three-dimensional ultrasound
}

Lissencephaly is a genetic heterogeneous autosomal recessive disorder characterized by the classical triad: brain malformations, eye anomalies, and congenital muscular dystrophy. Prenatal diagnosis is feasible by demonstrating abnormal development of sulci and gyri. Magnetic resonance imaging (MRI) may enhance detection of developmental cortical disorders as well as ocular anomalies. We describe a case of early diagnosis of lissencephaly type 2 detected at the time of routine second trimester scan by three-dimensional ultrasound and fetal MRI. Gross pathology confirmed the accuracy of the prenatal diagnosis while histology showed the typical feature of cobblestone cortex. As the disease is associated with poor perinatal prognosis, early and accurate prenatal diagnosis is important for genetic counseling and antenatal care. received

November 11, 2015

accepted

February 23, 2016

published online

April 18, 2016
DOI http://dx.doi.org/

10.1055/s-0036-1582126. ISSN 0100-7203.
Copyright $@ 2016$ by Thieme Publicações License terms Ltda, Rio de Janeiro, Brazil

(c) $(1) \$$ 


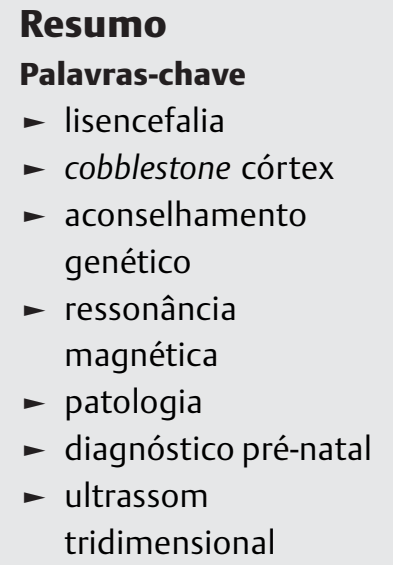

Lissencefalia são doenças genéticas autossômicas recessivas heterogêneas caracterizadas pela tríade clássica: malformações do cérebro, anomalias oculares e distrofia muscular congênita. Diagnóstico pré-natal é factível pela demonstração do desenvolvimento anormal de sulcos e giros. Ressonância magnética (RM) melhora a detecção de distúrbios do desenvolvimento cortical, bem como as anomalias oculares. Descrevemos um caso de diagnóstico precoce de lisencefalia tipo 2 detectado no momento do ultrassom morfológico de segundo trimestre pela ultrassonografia tridimensional e RM fetal. A macroscopia confirmou a acurácia do diagnóstico pré-natal, enquanto que a microscopia mostrou a típica característica de córtex em cobblestone. Como a doença está associada à um pobre prognóstico perinatal, o precoce e acurado diagnóstico pré-natal é importante para o aconselhamento genético e seguimento da gestação.

\section{Introduction}

Lissencephaly is a genetic heterogeneous autosomal recessive disorder characterized by the classical triad: brain malformations, eye anomalies, and congenital muscular dystrophy. ${ }^{1}$ This disease was first described by Walker ${ }^{2}$ in 1942 as lissencephaly; however, the spectrum of brain abnormalities is diverse, including Dandy-Walker syndrome and ventriculomegaly. ${ }^{3,4}$ The neuropathology of lissencephaly relies upon cortical dysplasia that results in neuroglial over-migration into the arachnoid space to form an extracortical layer that produces agyria and/or a "cobblestone" brain surface and ventricular enlargement. ${ }^{5}$ Radial glial cells play a central role in cerebral cortical development ${ }^{6}$ in addition, the basement membrane/glia limitans (BM/GL) located immediately below the pia mater serves as an anchor point for the end feet of radial glial cells and as a physical barrier to migrating neurons. ${ }^{7}$ Mutations in genes encoding BM constituents have been shown to disrupt BM integrity and result in disorganized cortical lamination..$^{8-10}$ Mutations in POMT1, POMT2, POMGNT1, LARGE, FKTN, and FKRP identified these diseases as $\alpha$-dystroglycanopathies. ${ }^{5}$ Mutations in the POMT1 (protein-O-mannosyltransferase 1) gene in the 9q34 chromosome region account for $\sim 20 \%$ of lissencephaly diseases; ${ }^{11}$ however, mutations in the LARGE (Acetylglucosaminyltransferase-like Protein) and FKRP (Fukutin-Related Protein) have also been described in the literature. ${ }^{12,13}$ In zebrafish, mutation in LAMB1 (laminin subunit 1), a glycoprotein of the basal lamina that influences cell proliferation, differentiation, migration, and adhesion, ${ }^{14}$ has been shown to cause cobblestone lissencephaly without muscular and ocular malformations. ${ }^{15}$ The main cortical fissures can be visualized through ultrasound from 18 weeks of gestation onwards; however, only at 30-32 weeks the main sulci/gyri can be visualized. ${ }^{16}$ Three-dimensional ultrasound was introduced in the obstetrics clinical practice in the mid-90's, and has been applied as adjuvant to 2DUS and magnetic resonance imaging (MRI) in several fetal brain malformations. However, the application of three-dimensional ultrasound (3DUS) in the rendering mode to assess the development of fetal sulci and gyri during pregnancy is still of limited application. ${ }^{17}$

\section{Case Report}

A 28 -year-old-woman, gravida 1, was referred for level II ultrasound examination at 21 weeks and 5 days of gestation for suspected severe hydrocephalus in the Department of Obstetrics and Gynecology, Ospedale Civile di Guastalla, AUSL Reggio Emilia, Reggio Emilia, Italy. Her past medical and family history was investigated and resulted uneventful, with no congenital anomalies. Consanguinity was also excluded. TORCH investigation showed no evidence of primary infection during pregnancy. Body mass index (BMI) was 24 $\mathrm{kg} / \mathrm{m}^{2}$, normal blood pressure and $75 \mathrm{~g}$ oral glucose tolerance test (OGTT) performed at the $16^{\text {th }}$ week of gestation for ethnicity resulted negative. Ultrasound examination was performed using Voluson E6 apparatus (GE, Milwaukee, WI) equipped with both transabdominal and transvaginal 2D/3D volumetric probes. Fetal biometry showed a growth within the range for the gestational age. Neuroscan using conventional 2DUS confirmed the diagnosis of a severe communicating hydrocephalus. As part of our protocol in case of detected brain malformations, dedicated 3DUS neuroimaging using surface rendering mode was performed and enabled, better than 2DUS, detection of a thin mantel of cortex with absent visualization of the parieto-occipital and calcarine fissures, findings consistent with pachygyria (-Fig. 1). There was associated posterior fossa abnormality characterized by cerebellar vermis hypoplasia with a transverse cerebellar diameter of $14 \mathrm{~mm}\left(<3^{\text {rd }}\right.$ percentile for expected gestational age). A prenatal ultrasound diagnosis of lissencephaly was prompted. A thorough anatomical survey excluded other malformations, including ocular, facial, cardiac or skeletal diseases. Following genetic counselling and the signed informed consent, an uneventful amniocentesis with fluorescence in situ hybridization (FISH) investigation was performed. Fetal karyotype resulted in $46, \mathrm{XY}$ and FISH excluded a 17p13.3 deletion or mutation in the LIS1 gene encoding for Miller-Dieker syndrome (lissencephaly type I). Fetal MRI was at that time arranged as complementary 


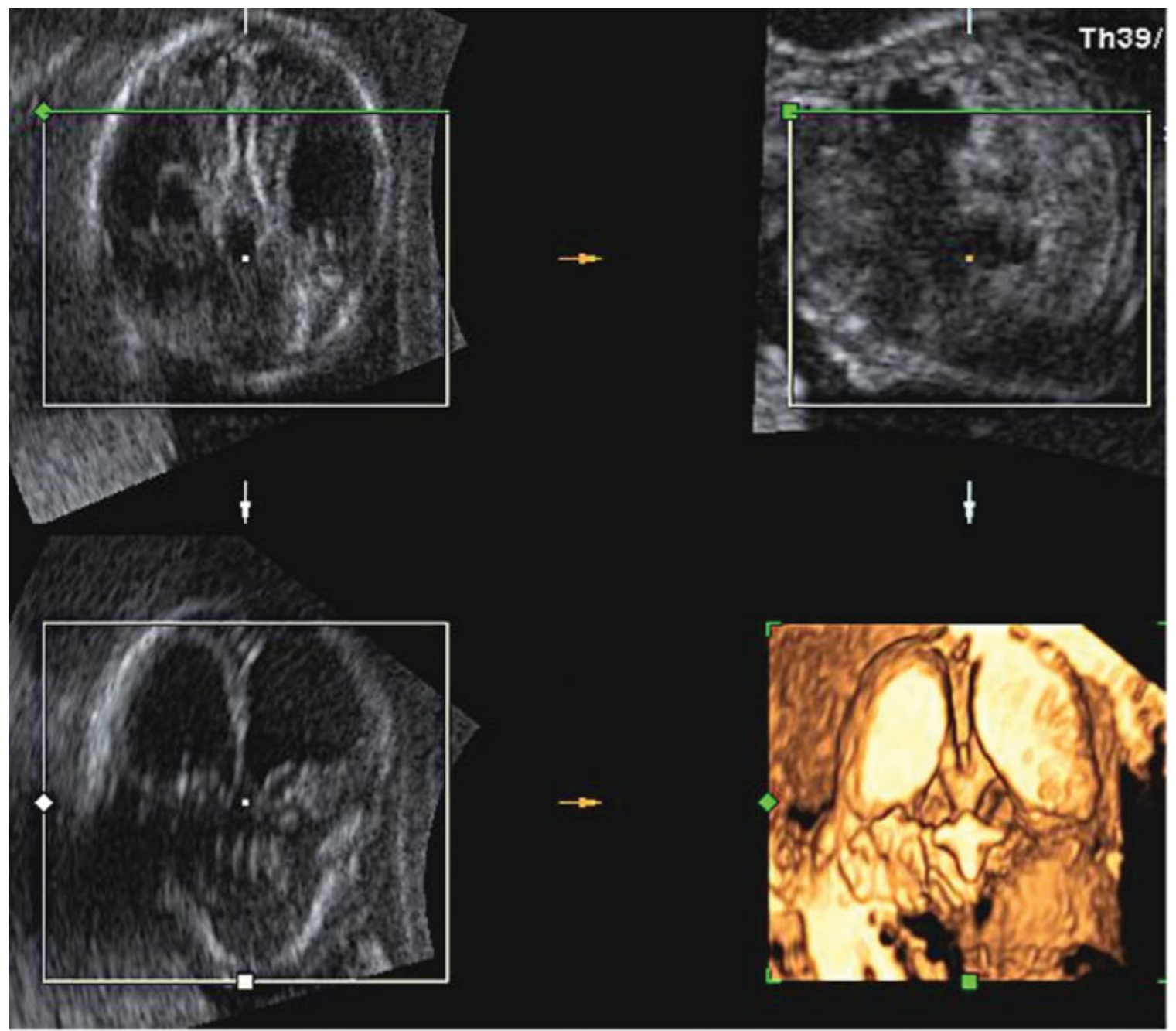

Fig. 1 Transabdominal three-dimensional ultrasound in rendering mode performed at 21 weeks and 5 days of gestation. Navigation within the volume detected severe communicating hydrocephalus. Abnormal posterior fossa with cerebellar hypoplasia was also detected, as well as a thin mantel of cortex. No parieto-occipital fissure or calcarine sulcus could be observed.

diagnostic investigation. The MRI equipment was a 1.5 Tesla Signa Twin Speed superconducting system (GE, Milwaukee, WI) using an 8-element phased array surface coil. Standard single-shot fast spin echo (SSFSE) imaging was performed in the fetal sagittal, coronal, and axial planes using the following parameters: repetition time (RT), single-shot, echo time (ET), 80 milliseconds; TR/TE, Infinite/90; bandwidth, $32 \mathrm{kHz}$; field of view, $30 \times 30 \mathrm{~cm}$; matrix, $256 \times 192$; gap, $1.5 \mathrm{~mm}$; number of excitations, 0.5 ; refocusing pulse of less than 180 degrees; slice thickness, $4 \mathrm{~mm}$; and 0.6 second per slice, echo-train length, $72 ; 1$ signal acquired. Fetal MRI confirmed the ultrasound findings of communicating hydrocephalus with posterior fossa anomalies including cerebellar vermal hypoplasia, brainstem hypoplasia and pachygyria (-Fig. 2). Post-test counselling by the multi-specialist team was provided due to poor perinatal prognosis of the disease, parents requested pregnancy termination that was achieved after hospitalization and accomplished using vaginal PGE administration. Gross pathology documented a visible Sylvian fissure but with a vertical direction, wide communication of the dilated frontal horns with dysplasia of the anterior wall of the cavum septi pellucidi (absent, a finding also seen in septo-optic dysplasia and semilobar holoprosencephaly), normal corpus callosum and dilated fourth ventricle. Cerebellar hypoplasia was confirmed.

Histology showed the typical cobblestone pattern of the cerebral cortex in lissencephaly type 2. Cortical layers were absent and there was an irregular scramble of neurons mixed with underlying white matter. These findings represented the neuropathology clues of the so-called cobblestone cortex at cellular level. Normal fetal cortex at 22 weeks was still unlayered, but was well organized, and future neurons were orderly piled up (-Fig. 3 ).

Macroscopy of fetal brain showed that the cortical surface was smooth (agyria). The normal gray-white matter distribution was not recognizable, but there was evidence of a discontinuous subcortical gray line. Lateral ventricles were enlarged and hippocampi were upright (-Fig. 4).

\section{Discussion}

Lissencephaly is a generic term used to describe different congenital brain malformations resulting from disorders in the migration of neocortical neurons during the $3^{\text {rd }}$ and $4^{\text {th }}$ 


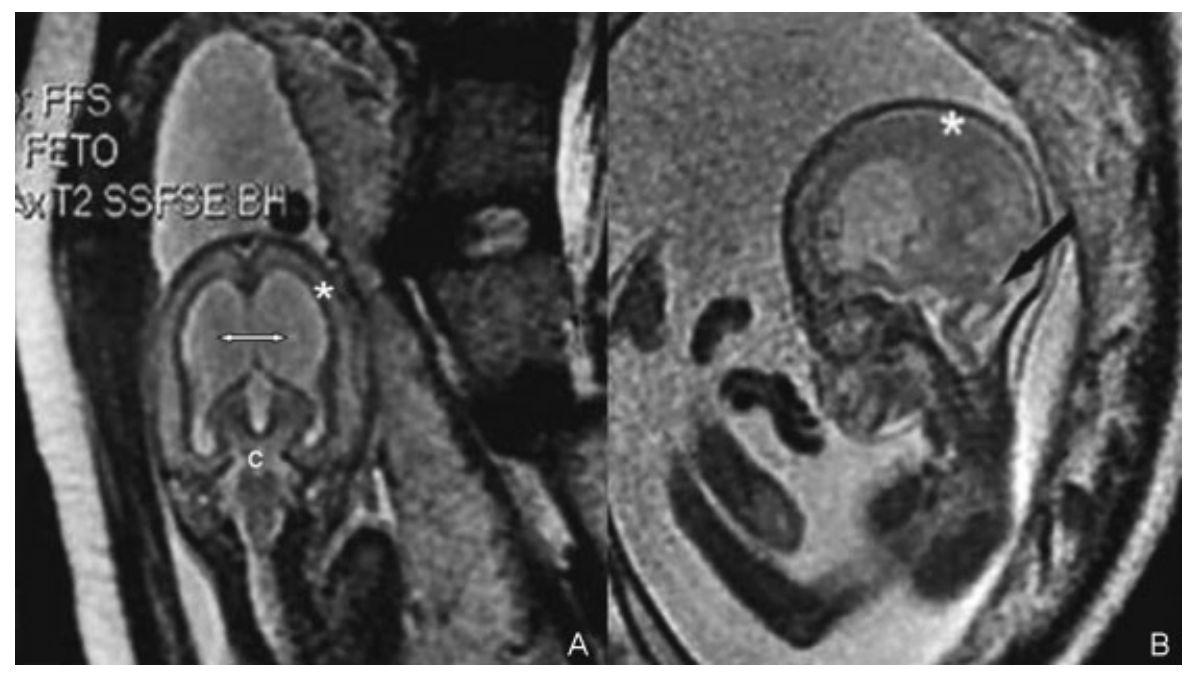

Fig. 2 (A) T2-weighted fetal magnetic resonance imaging confirmed in coronal section the findings of communicating hydrocephalus (double arrow), cerebellar hypoplasia (c) and pachygyria (*); (B) T2-weighted image in sagittal plane showed brainstem hypoplasia with typical "Z"shaped morphology (black arrow) and dilated fourth ventricle. The mantel of the cerebral cortex was characterized by pachygyria (asterisk). A diagnosis of lissencephaly was elicited.

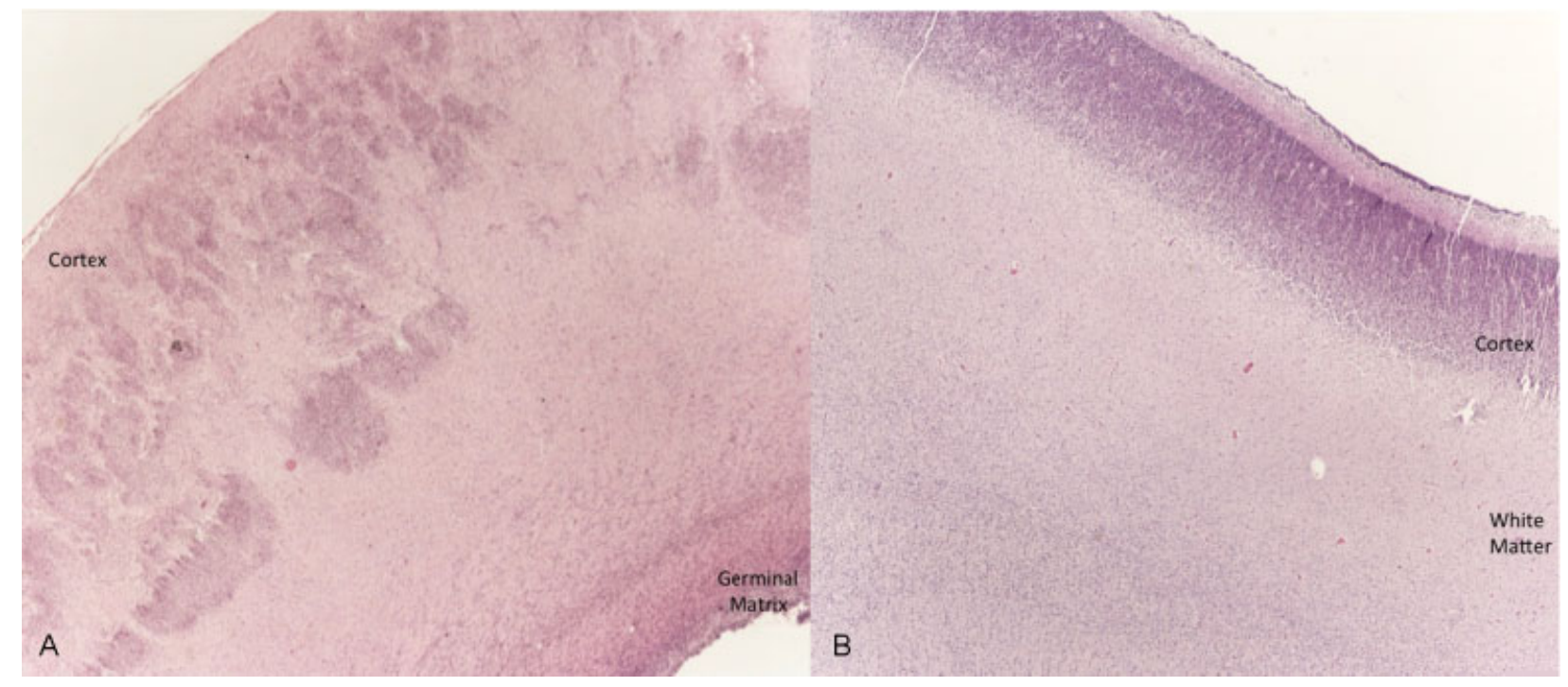

Fig. 3 (A) Histology shows the typical cobblestone pattern of the cerebral cortex in lissencephaly type 2. Cortical layers are absent and there is an irregular scramble of neurons mixed with underlying white matter. (B) Histology shows normal fetal cortex at 22 weeks of gestation. The primitive neurons, migrating from the germinal matrix, are orderly piled up. No definite layers are recognizable yet.

months of gestation. ${ }^{18}$ Lissencephaly has been divided in three sub-types. Lissencephaly type 1 can be isolated or associated with several phenotypes overlapping those of Miller-Dieker or Norman-Roberts syndrome. Miller-Dieker syndrome is a genetic disorder associated with a mutation or deletion at chromosome $17 \mathrm{p} 13.3 .{ }^{19}$ a finding that was excluded in our observation by FISH. In $50 \%$ of cases, lissencephaly type 2 is characterized by a disorganized, unlayered cortex, ventriculomegaly and Dandy-Walker syndrome. Aqueduct stenosis or posterior encephalocele are also sometimes found. ${ }^{20}$ Over the last decade, lissencephaly type 3 has been used to describe a phenotype lacking radiologic and pathologic findings, as seen in type 1 or lissencephaly type 2 . This latter form is a lethal familial syndrome that comprises microcephaly/lissencephaly and a spectrum of abnormalities lined to a severe fetal akinesia deformation sequence. ${ }^{21}$

Prenatal diagnosis of lissencephaly and overlapping syndromes has been described since the mid-1980s by conventional 2DUS. ${ }^{22}$ Lissencephaly is usually detected late in gestation using $2 \mathrm{DUS}^{2}$ and ventriculomegaly is described in almost all cases diagnosed prenatally. ${ }^{23-25}$ Although the neuronal migration process reaches its peak at around 20 weeks of gestation, the sensitivity of ultrasound in the prenatal diagnosis of abnormal cortical development is low. However, Malinger et $\mathrm{al}^{26}$ demonstrated that dedicated neurosonography using transabdominal route showed good level of agreement between prenatal diagnosis of abnormal cortical development and pathology examination, 


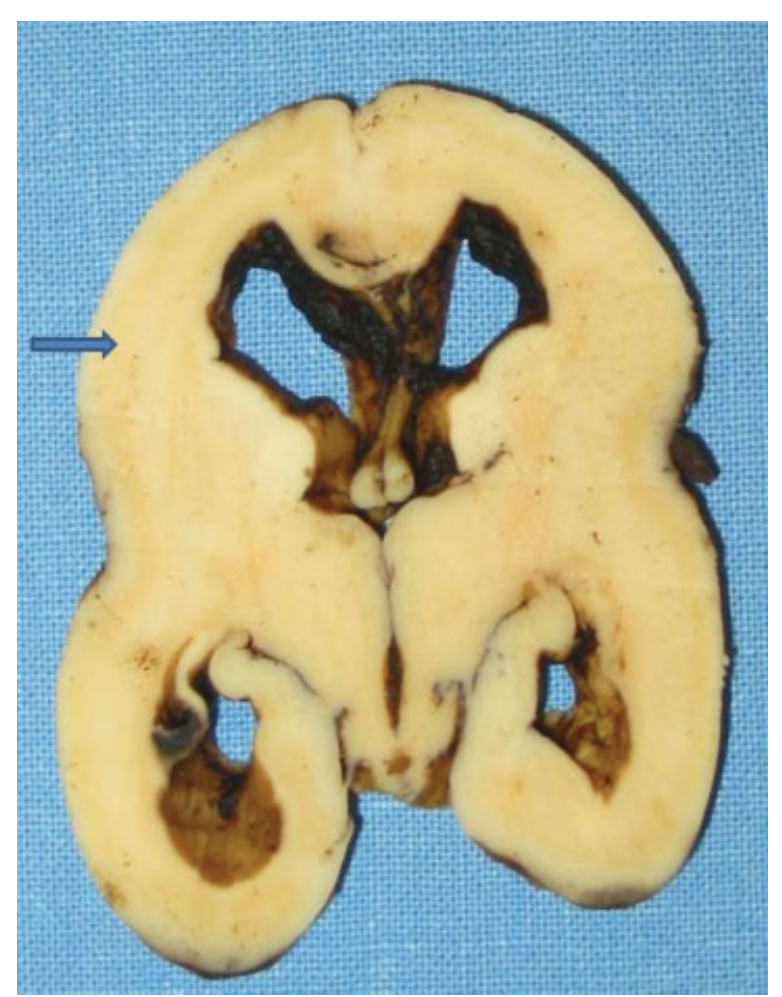

Fig. 4 Macroscopy of fetal brain shows a coronal section through the midline. The cortical surface is smooth (agyria). The normal graywhite matter distribution is not recognizable, but there is evidence of a discontinuous subcortical gray line (arrow). Lateral ventricles are enlarged and hippocampi are upright.

both macro- and microscopic. Toi et $\mathrm{al}^{27}$ assessed the gestational age by which sulci were visible using transabdominal ultrasound in 50 normal fetuses between 15 weeks and 6 days and 29 weeks and 6 days of gestation. These authors demonstrated that sulci were always visible beyond week 20 , and specifically the parieto-occipital fissure $>20 \mathrm{w} 5 \mathrm{~d}$, calcarine sulcus $>21 \mathrm{w} 9 \mathrm{~d}$, cingulate sulcus $>24 \mathrm{w} 3 \mathrm{~d}$ and convexity sulci $>27 \mathrm{w} 9 \mathrm{~d} .{ }^{27}$

Strigini et $\mathrm{al}^{28}$ reported a case at week 26 of gestation in which 2DUS showed enlargement of the lateral and third ventricles, separated cerebellar lobes with no detectable vermian structure and an enlarged retropulvinar cistern.

Fetal MRI enhanced the prenatal ultrasound diagnostic accuracy of lissencephaly by showing a kinked "Z"-shaped brainstem, with bifid pons and medulla oblongata. These anatomical details were undiagnosed on 2D/3DUS, confirming the role of antenatal MRI as a complementary diagnostic tool in all cases of brain pathology detected by ultrasound. Although neuroscan for assessment of CNS malformations is routinely performed by 2DUS, 3DUS, with its applications such as multiplanar mode, reformatting/reslicing techniques, tomographic ultrasound imaging (TUI) and volume calculation may potentially aid the prenatal detection of brain anomalies and may be complemented by fetal MRI. ${ }^{29-32}$ As cortical and sulcus formation reflect the maturation of the brain, MRI provides most accurate information of sulci and gyri development compared with ultrasound, as visibility is not affected by cranial bones with near reverberation artifacts or fetal position. Ghai et $\mathrm{al}^{33}$ detected specific patterns of the development of sulci by 2DUS or MRI in fetuses with lissencephaly. Normally, the cerebral cortex develops in three overlapping stages: cell proliferation, neuronal migration, and cortical organization. Opposite to that, in cobblestone lissencephaly the cerebral cortex shows combined agyria and pachygyria, as well as polymicrogyria with a pebbled surface.

MRI findings consistent with cobblestone lissencephaly may be white matter signal abnormality, an irregular layer of ectopic neurons, corpus callosum hypoplasia, cerebellar hemisphere and vermis hypoplasia, brainstem hypoplasia with "Z"-shaped brainstem or notched pons. ${ }^{34}$ In the cases in which fetal MRI cannot be arranged, 3DUS in the rendering mode has shown to improve the visualization of sulci and gyri, and this approach may be useful as a complementary diagnostic tool in the prenatal detection of cortical development disorders. ${ }^{15}$

Although very recently, Lacalm et al. ${ }^{35}$ have reported ultrasound pattern of outer echogenic band reducing pericerebral spaces (corresponding to an infra and supratentorial extracortical layer of neuroglial over-migration on histology) and a " $Z$ " shape-appearance of the brainstem at 14 weeks of pregnancy; caution must be exerted as the developing brain is still smooth and only severe forms, such as agyria, are likely to be diagnosed by 2DUS or early second trimester MRI.

Differential diagnoses include Dandy-Walker complex (DWC) and septo-optic dysplasia (SOD). Dandy-Walker complex refers to a spectrum of abnormalities of the posterior fossa categorized as classic DWM (enlarged posterior fossa, complete or partial agenesis of the cerebellar vermis, elevated tentorium); Dandy-Walker variant (variable hipoplasia of cerebellar vermis, with or without enlargement of the posterior fossa); and megacisterna magna (enlarged cisterna magna, with unaffected cerebellar vermis and fourth ventricle). ${ }^{36,37}$ Septo-optic dysplasia or De Morsier syndrome (OMIM \#182230) can be caused by mutation in the homebox gene HESX1 on chromosome 3p14 and it is clinically characterized by any combination of optic nerve hypoplasia, pituitary gland hypoplasia, and midline abnormalities of the brain, including absence of the corpus callosum and the septum pellucidum. ${ }^{38}$ Cortical abnormalities in SOD may vary, ranging from schizencephaly, polymicrogyria and focal laminar disorganization of the cortical layers.

In summary, we have described an early second trimester diagnosis of lissencephaly using 3DUS and fetal MRI. Magnetic resonance imaging enhanced the accuracy of the ultrasound by detecting the abnormalities involving the brainstem, improved counselling accuracy and aided the parent's decision-making process. Molecular genetic testing excluded Miller-Dieker lissencephaly, while neuropathology demonstrated a cellular neuronal pattern characteristic of a cobblestone cortex. We believe that dedicated 3DUS neuroscan and MRI are useful imaging modalities that contribute to the accurate detection of cortical disorders in the fetus even at early stages of development. 


\section{Note}

Study performed at the Dipartimento di Ostetricia e Ginecologia, Ospedale Civile di Guastalla, AUSL Reggio Emilia, Reggio Emilia, Italy.

\section{References}

1 Vajsar J, Schachter H. Walker-Warburg syndrome. Orphanet J Rare Dis 2006; $1: 29$

2 Walker W. Lissencephaly. Arch Neurol Psychiatry 1942;48(1): 13-29

3 Monteagudo A, Alayón A, Mayberry P. Walker-Warburg syndrome: case report and review of the literature. J Ultrasound Med 2001;20(4):419-426

4 Blin G, Rabbé A, Ansquer Y, Meghdiche S, Floch-Tudal C, Mandelbrot L. First-trimester ultrasound diagnosis in a recurrent case of Walker-Warburg syndrome. Ultrasound Obstet Gynecol 2005; 26(3):297-299

5 Vuillaumier-Barrot S, Bouchet-Séraphin C, Chelbi M, et al. Identification of mutations in TMEM5 and ISPD as a cause of severe cobblestone lissencephaly. Am J Hum Genet 2012;91(6):1135-1143

6 Hansen DV, Lui JH, Parker PR, Kriegstein AR. Neurogenic radial glia in the outer subventricular zone of human neocortex. Nature 2010;464(7288):554-561

7 Siegenthaler JA, Pleasure SJ. We have got you 'covered': how the meninges control brain development. Curr Opin Genet Dev 2011; 21(3):249-255

8 Labelle-Dumais C, Dilworth DJ, Harrington EP, et al. COL4A1 mutations cause ocular dysgenesis, neuronal localization defects, and myopathy in mice and Walker-Warburg syndrome in humans. PLoS Genet 2011;7(5):e1002062

9 Costell M, Gustafsson E, Aszódi A, et al. Perlecan maintains the integrity of cartilage and some basement membranes. J Cell Biol 1999;147(5):1109-1122

10 Luo R, Jeong SJ, Jin Z, Strokes N, Li S, Piao X. G protein-coupled receptor 56 and collagen III, a receptor-ligand pair, regulates cortical development and lamination. Proc Natl Acad Sci U S A 2011;108(31):12925-12930

11 Beltrán-Valero de Bernabé D, Currier S, Steinbrecher A, et al. Mutations in the $\mathrm{O}$-mannosyltransferase gene POMT1 give rise to the severe neuronal migration disorder Walker-Warburg syndrome. Am J Hum Genet 2002;71(5):1033-1043

12 van Reeuwijk J, Grewal PK, Salih MA, et al. Intragenic deletion in the LARGE gene causes Walker-Warburg syndrome. Hum Genet 2007;121(6):685-690

13 Godfrey C, Escolar D, Brockington M, et al. Fukutin gene mutations in steroid-responsive limb girdle muscular dystrophy. Ann Neurol 2006;60(5):603-610

14 Lee J, Gross JM. Laminin beta 1 and gamma1 containing laminins are essential for basement membrane integrity in the zebrafish eye. Invest Ophthalmol Vis Sci 2007;48(6):2483-2490

15 Radmanesh F, Caglayan AO, Silhavy JL, et al. Mutations in LAMB1 cause cobblestone brain malformation without muscular or ocular abnormalities. Am J Hum Genet 2013;92(3):468-474

16 Cohen-Sacher B, Lerman-Sagie T, Lev D, Malinger G. Sonographic developmental milestones of the fetal cerebral cortex: a longitudinal study. Ultrasound Obstet Gynecol 2006;27(5):494-502

17 Rolo LC, Araujo Júnior E, Nardozza LM, de Oliveira PS, Ajzen SA, Moron AF. Development of fetal brain sulci and gyri: assessment through two and three-dimensional ultrasound and magnetic resonance imaging. Arch Gynecol Obstet 2011;283(2):149-158

18 van der Knaap MS, Valk J. Classification of congenital abnormalities of the CNS. AJNR Am J Neuroradiol 1988;9(2):315-326

19 Fong KW, Ghai S, Toi A, Blaser S, Winsor EJ, Chitayat D. Prenatal ultrasound findings of lissencephaly associated with Miller-Die- ker syndrome and comparison with pre- and postnatal magnetic resonance imaging. Ultrasound Obstet Gynecol 2004;24(7): 716-723

20 Kojima K, Suzuki Y, Seki K, et al. Prenatal diagnosis of lissencephaly (type II) by ultrasound and fast magnetic resonance imaging. Fetal Diagn Ther 2002;17(1):34-36

21 Allias F, Buenerd A, Bouvier R, et al. The spectrum of type III lissencephaly: a clinicopathological update. Fetal Pediatr Pathol 2004;23(5-6):305-317

22 Crowe C, Jassani M, Dickerman L. The prenatal diagnosis of the Walker-Warburg syndrome. Prenat Diagn 1986;6(3):177-185

23 Rodgers BL, Vanner LV, Pai GS, Sens MA. Walker-Warburg syndrome: report of three affected sibs. Am J Med Genet 1994;49(2): 198-201

24 Chitayat D, Toi A, Babul R, et al. Prenatal diagnosis of retinal nonattachment in the Walker-Warburg syndrome. Am J Med Genet 1995;56(4):351-358

25 Gasser B, Lindner V, Dreyfus M, et al. Prenatal diagnosis of WalkerWarburg syndrome in three sibs. Am J Med Genet 1998;76(2): 107-110

26 Malinger G, Kidron D, Schreiber L, et al. Prenatal diagnosis of malformations of cortical development by dedicated neurosonography. Ultrasound Obstet Gynecol 2007;29(2):178-191

27 Toi A, Lister WS, Fong KW. How early are fetal cerebral sulci visible at prenatal ultrasound and what is the normal pattern of early fetal sulcal development? Ultrasound Obstet Gynecol 2004;24(7): 706-715

28 Strigini F, Valleriani A, Cecchi M, et al. Prenatal ultrasound and magnetic resonance imaging features in a fetus with WalkerWarburg syndrome. Ultrasound Obstet Gynecol 2009;33(3): 363-365

29 Tonni G, Grisolia G. Dilated intracranial translucency and Blake's pouch cyst: first-trimester ultrasound markers of occipital cephalocele diagnosed using novel three-dimensional reslicing technique. J Clin Ultrasound 2014;42(3):157-161

30 Tonni G, Grisolia G, Sepulveda W. Second trimester fetal neurosonography: reconstructing cerebral midline anatomy and anomalies using a novel three-dimensional ultrasound technique. Prenat Diagn 2014;34(1):75-83

31 Haratz KK, Oliveira PS, Rolo LC, et al. Fetal cerebral ventricle volumetry: comparison between 3D ultrasound and magnetic resonance imaging in fetuses with ventriculomegaly. J Matern Fetal Neonatal Med 2011;24(11):1384-1391

32 Abe S, Takagi K, Yamamoto T, Okuhata Y, Kato T. Assessment of cortical gyrus and sulcus formation using MR images in normal fetuses. Prenat Diagn 2003;23(3):225-231

33 Ghai S, Fong KW, Toi A, Chitayat D, Pantazi S, Blaser S. Prenatal US and MR imaging findings of lissencephaly: review of fetal cerebral sulcal development. Radiographics 2006;26(2):389-405

34 Hoffman JD, Park JJ, Schreiber-Agus N, et al. The Ashkenazi Jewish carrier screening panel: evolution, status quo, and disparities. Prenat Diagn 2014;34(12):1161-1167

35 Lacalm A, Nadaud B, Massoud M, Putoux A, Gaucherand P, Guibaud L. Prenatal diagnosis of cobblestone lissencephaly associated with Walker-Warburg syndrome based on a specific sonographic pattern. Ultrasound Obstet Gynecol 2016;47(1):117-122

36 Harwood-Nash DC, Fitz CR. Neuroradiology in Infants and Children. St. Louis: Mosby; 1976

37 Tonni G, Grisolia G. Ultrasound diagnosis of central nervous system anomalies (bifid choroid plexus, ventriculomegaly, Dandy-Walker malformation) associated with multicystic dysplastic kidney disease in a trisomy 9 fetus: case report with literature review. J Clin Ultrasound 2013;41(7):441-447

38 Dattani MT, Martinez-Barbera JP, Thomas PQ et al. Mutations in the homeobox gene HESX1/Hesx1 associated with septo-optic dysplasia in human and mouse. Nat Genet 1998;19(2):125-133 